WIDER Working Paper 2020/121

\title{
Polarization in the South African labour market
}

Economy-wide scenarios

Rob Davies ${ }^{1}$ and Dirk van Seventer ${ }^{2}$

October 2020 
Abstract: Technical change impacts both the employment intensity of production and the composition of occupations and skills of employment. Artificial intelligence, automation, and robots are already leading to machines undertaking routinizable tasks previously carried out by workers. This can lead to labour market polarization, with jobs in the middle of the wage/occupation distribution being lost relative to those at the top and bottom ends. South Africa may be a latecomer to this process, but there is already evidence it is under way and may accelerate. We offer an economy-wide perspective on this process. A standard comparative static computable general equilibrium framework is employed to explore first- and second-order impacts of equipment substituting for routine labour in production. We find that second-order economywide effects may offset some but not all of the first-order losses in routine jobs.

Key words: labour market, polarization, computable general equilibrium, tasks, South Africa

JEL classification: C68, J23, J24, O55

${ }^{1}$ Department of Finance and Management, SOAS, University of London, London, UK, corresponding author: robdavieszim@gmail.com; ${ }^{2}$ UNU-WIDER, Helsinki, Finland

This study has been prepared within the UNU-WIDER project Southern Africa-Towards Inclusive Economic Development (SA-TIED).

Copyright (C) UNU-WIDER 2020

Information and requests: publications@wider.unu.edu

ISSN 1798-7237 ISBN 978-92-9256-878-8

https://doi.org/10.35188/UNU-WIDER/2020/878-8

Typescript prepared by Gary Smith

The United Nations University World Institute for Development Economics Research provides economic analysis and policy advice with the aim of promoting sustainable and equitable development. The Institute began operations in 1985 in Helsinki, Finland, as the first research and training centre of the United Nations University. Today it is a unique blend of think tank, research institute, and UN agency — providing a range of services from policy advice to governments as well as freely available original research.

The Institute is funded through income from an endowment fund with additional contributions to its work programme from Finland, Sweden, and the United Kingdom as well as earmarked contributions for specific projects from a variety of donors.

Katajanokanlaituri 6 B, 00160 Helsinki, Finland

The views expressed in this paper are those of the author(s), and do not necessarily reflect the views of the Institute or the United Nations University, nor the programme/project donors. 
This paper explores potential consequences of new technologies clustered around automation and information for jobs and inequality in South Africa.

Occupational classification schemes place occupations that require higher skills and earn higher wages (the two are not perfectly correlated) at the top and have them both decrease as we move 'down' the classification. It has been suggested that the cluster of new computer-based technologies (comprising automation, machine learning, artificial intelligence, and robotics-in this paper referred to collectively as 'automation') displaces workers in the middle of this distribution and creates jobs at each end. This phenomenon is often referred to as labour market polarization, and can show up in occupational employment patterns, the occupational wage structure, or both. There is a broad consensus that there has been polarization in developed countries (e.g., Autor and Dorn 2013; Eurofound 2016; Goos et al. 2014), although there is some recent dissent (e.g. Oesch and Piccitto 2019).

South Africa faces high unemployment and a skills shortage simultaneously. Our intuition is that, while the technological forces leading to polarization elsewhere may polarize demand for skills, in such an economy the response will be wage increases at the top end as the demand for skills runs into the skills constraint, and (at best) job expansion with stagnant wages at the bottom. The impact this has on South Africa's income distribution—already highly unequal—will depend on what it does to employment at the various parts of the distribution.

These impacts can be mitigated or compounded by policy, especially regarding skills development, and can also be related to structural change in the economy that is potentially subject to policy choices. However, as we note below, the offsetting effects of skills development may themselves be constrained by the capacity of displaced workers to acquire appropriate new skills.

Although the impact of new technologies is initially at the level of the firms and sectors adopting them, polarization, if it occurs, is an economy-wide phenomenon. We therefore need an economywide approach to analyse it, in addition to more focused sector studies. In this paper, we use a computable general equilibrium model to explore possible scenarios. Studies in developed countries can draw on large, disaggregated time series datasets to unpack what the effects of the new technologies have been. This is difficult in South Africa for two reasons. First, the data are more limited. We have explored elsewhere some of the data available (Davies and van Seventer 2020), which we hope raises sufficient warning flags around the usefulness of existing data for this purpose.

Second, we suggest that technology in South Africa lags that of OECD countries, and that South Africa is at an earlier phase in the diffusion of these technologies (Harding and Rattsø 2009). If this is so, the data, even were they available, would not show as much polarization as has been found in developed countries and would thus be of little use as a guide to what might be coming. What is perhaps more useful for policy thinking are scenarios sketching out potential future paths and, most importantly, the features of the economy that drive them. 
Polarization can be interpreted in different ways. Although the two are obviously related, wage or income polarization can be distinguished from employment polarization. ${ }^{1}$ In South Africa, both van der Linde and Bhorat et al. have focused on the former (Bhorat et al. 2020; van der Linde 2015), while Davies and van Seventer focus on the latter (Davies and van Seventer 2020). All three of these papers look at past trends which, as we have argued above, may not be a useful guide to the future.

Our paper should thus be regarded as exploratory. We hope it will stimulate further research to improve understanding of the phenomenon we examine and will improve gathering the data needed.

The paper continues in the next section with a simple narrative of how new technology impacts the economy. This narrative is informed by our reading of the literature, which we discuss in a selective and non-exhaustive way in Section 3, highlighting concerns of particular relevance to South Africa. Our opening narrative informs our modelling approach. In Section 4 we discuss a few technicalities relating to the framework for economy-wide modelling of these issues. Section 5 then presents some scenarios based on a model. We also examine some potential areas for policy interventions. Section 6 concludes, suggesting ways forward for both further investigation and policy directions.

\section{$2 \quad$ Automation and jobs: a simple narrative ${ }^{2}$}

When thinking about the impact of automation on labour in the economy as a whole, it is useful to distinguish between the automation industries - those engaged in producing the robots and software, installing them, and so on-and the automating industries- those using the robots and software to make other products. Our primary concern in this paper is with technology change in the automating industries and their economy-wide impacts.

Clearly, the rise of automation industries creates jobs in the same way that the expansion of any other sector does. There is nothing specific about the new technology in this context that makes it any different from the establishment or expansion of any other capital goods sector. As with capital goods, this is driven by a derived demand. That demand could come from abroad, with South Africa positioning itself as a producer of automation for the rest of the world. But that is a different story from the one we wish to explore. Whether there is a domestic demand for automation sufficient to drive a cost-competitive automation industry depends on the adoption of automating technologies within South Africa. So the first step in examining automation in South Africa is to look at the consequences of adopting new technologies. The net effect on economywide employment might be less than the direct effect on the automation industries itself. If automation capital displaces older capital, the firms producing the older capital will close down (or switch into producing automation machines). So there may well be some displacement. In this

\footnotetext{
${ }^{1}$ A distinction might also be made between relative and absolute polarization. Most of the literature suggests that either wages or employment will grow more slowly in the middle of the distribution than at the two ends (relative polarization). However, it appears sometimes to be interpreted to imply an absolute decline of the two.

2 The following account draws heavily on a number of key papers in the literature, including Autor (2013), Autor et al. (2003), Acemoglu and Autor (2011), Acemoglu and Restrepo (2018, 2019), and Caselli and Manning (2019).
} 
study we largely ignore these effects, ${ }^{3}$ focusing initially on the impacts initiated from inside the automating industries.

New technology enters the economy as firms adopt it, so it is appropriate to begin tracing the economy-wide impact at the level of the firm. The firm produces an output sold on the market. Its production process requires a number of tasks to be completed. For the moment we do not worry about the precise definition or measurement of tasks, but use an intuitive understanding. The required tasks can be carried out by people and by machines. Some require human input or are completely mechanized, while others could be carried out by either. Technological change means that machines are developed that can take over some tasks currently undertaken by people. It may be that in the process of replacement the tasks change; machines do not simply replicate the actions of humans, but may do them differently.

We follow the literature in classifying human tasks into three broad classes: abstract tasks, manual tasks, and routine tasks (Autor et al. 2003; Autor 2013). Abstract tasks require human thought and management. Manual tasks are those that require human contact as part of their output. Routine tasks are those for which a full and precise set of instructions for carrying them out can be written. This makes it possible to assign these tasks to machines that simply follow the instructions. Some routine tasks will be carried out by humans and some by machines. All tasks are combined with each other, and with other capital, to produce the firm's output. ${ }^{4}$

Technological change leads to the firm replacing routine human labour with machines because it is more cost effective. ${ }^{5}$ Carrying out the set of routine tasks becomes cheaper. The cost of producing the final output falls. In the simplest case, there may be no change in output or in the demand for abstract or manual labour. Less routine labour is required, but that simply reflects a change in the composition of routine labour and machines that go into completing the routine tasks. Abstract and manual labour, and other capital, are still needed to produce the final good and are still needed in the same quantity.

In this simplistic case, routine labour has been displaced by machines. The production process still requires the same tasks to be completed, but machines rather than workers do them. Were this the whole story, the spectre of automation leading to massive unemployment would be right. However, of course, it is not the whole story.

First, it assumes that the final output is fixed. If it becomes cheaper to carry out the routine tasks, the firm can produce its final output more cheaply. If it passes this cost reduction on to its customers, demand and output can rise. ${ }^{6}$ Increasing output will raise demand for all tasks.

\footnotetext{
${ }^{3}$ One reason for not looking at the automation aspect is that many of these jobs will likely be created outside South Africa, given our assumption of imported technology. However, it is possible that although the technology evolves elsewhere, the production of machines embodying the technology takes place in South Africa.

${ }^{4}$ The role of 'other capital' in this task-based approach is somewhat problematic. 'Other capital' includes structures. Do structures undertake tasks? Or are they complementary inputs into all the other tasks? Should we think of it as firm infrastructure?

${ }^{5}$ We use the circumlocution 'more cost effective' rather than 'cheaper' because, as we discuss later, although there may be reasons for adopting it other than direct cost, these can be interpreted as related to overall costs.

${ }^{6}$ We can see issues of competition and monopoly enter here. A monopoly might simply take the reduced costs as increased rent.
} 
Second, technical change typically creates new tasks. Some of these will be carried out by humans. At the time of adoption of the new technology, these tasks will, by definition, not be routinizable tasks, but rather abstract or manual. ${ }^{7}$

At the level of the firm, therefore, it is likely that automation not only displaces some tasks but also expands the demand for some existing tasks and creates new ones (Acemoglu and Restrepo 2019).

Economists raised in the tradition of production functions may wonder why the production process does not become more routine-task intensive if routine tasks can now be undertaken more cheaply? Why is there not a shift away from abstract and manual labour towards routine? Essentially, this is by assumption in this narrative. We assume that tasks are required in fixed proportion to each other. In this simplistic set-up we can think of production as requiring, say, completion of nine tasks, of which three are abstract, three are routine, and three are manual. If all three routine tasks are done by machines, we still need the three abstract and three manual tasks to be completed. All that happens in this case is that the three routine tasks are carried out more cheaply by machines.

A complication in this task-based story is that while it may tell us something about the firm's demand for tasks, we cannot translate that directly into jobs and employment. Although the production process can be conceived of as an assemblage of tasks, tasks themselves do not map one-to-one to people. The firm needs people with the appropriate skills to carry out tasks, but often the skills for several tasks are bundled into a single person. We associate a collection of skills with an occupation. When the firm hires a person to carry out a task, they hire capacity to do a number of other tasks. The rise of the gig economy and zero-hour contracts might be changing this, but typically a firm hires a person in an occupation and thus acquires access to a range of skills and task capabilities.

It is not clear which effects will dominate in this stylized description of how the process works at the level of the firm. That is an empirical question and depends on the exact nature of the processes. What is the extent of the displacement? What is the complementarity between routine and other types of task? Answering these questions requires very detailed empirical work collecting the relevant data. While such work is being undertaken in South Africa, it has not reached a stage at which we can use it. Such work would provide information about the key features of the process, at a microeconomic firm level, that we need to feed into the economy-wide model we use here. This paper is concerned with how these different aspects interact. What are the drivers of the size of the effects?

The foregoing narrative focuses on the impacts on the automating firm itself. A number of other channels open up once we place these effects into an economy-wide context. These include:

\footnotetext{
${ }^{7}$ There is an interesting question: if the new technology displaces an abstract job, should we have classified that job as routinizable? This is purely definitional. In standard production models, capital can replace labour because it is assumed there are a range of blueprints available, some more capital-intensive than others, and the firm selects from them based on cost. Although labour is displaced, it has not typically been characterized as capital taking away the jobs of labour in the same way that automation is.

Of course, future technological change may turn non-routine tasks created at present into routine tasks in the future. One of the features of the task-based approach is the extent to which the early literature underestimated the scope for displacement of what were regarded as abstract tasks, particularly because of the speed of development of artificial intelligence.
} 
- Impacts on other sectors through forward linkages. Automation does not simply replace labour but, presumably, reduces costs (otherwise the firm might not automate). If these cost reductions are passed on, firms supplied by the automating firm may be stimulated. Acemoglu and Restrepo (2018) speak of these effects as productivity effects. We expect automation in sectors with strong forward linkages to have bigger economy-wide effects than automation in those with weak forward linkages.

- Impacts on other sectors through backward linkages. Automation can create demands for sectors supplying the automating firm. This could be through demand for the equipment and services related directly to automation itself, through investment or through operating expenses. In so far as the automation leads to increased output from the automating firm, there will also be knock-on effects to suppliers of regular inputs unrelated to automation. However, these may not all be positive. There may be some inputs that were specifically associated with labour tasks that have now been automated. Paperless offices are related to automation. There may be a rise in energy inputs and a reduction in inputs such as uniforms, desks, etc. We do not incorporate these effects into our modelling, primarily because we have no information about them. This is where research at a microeconomic level—possibly exploring value chain implications of automation—is needed.

- Broader economy-wide impacts. There may be second- and third-order effects such as changes in consumption demands related to both relative price changes and impacts on income distribution. In an open economy, there may be effects operating through relative price changes in traded and non-traded goods. We think these are likely to be small relative to the more direct effects.

The size of the automating sector(s) will also determine general equilibrium effects. The ripple effects across the economy of a large sector will be greater than those of a small one, even if they are embedded in the structure of the economy in similar ways.

Our focus is on the consequences of these processes as they roll out in the South African economy. In particular, we are concerned with the consequences for South Africa of automation of production processes in South Africa. Of course there are consequences that flow from automation adoption elsewhere in the world. There is some literature that suggests that global automation forces have differing impacts in developed and less developed countries. The argument is that the negative impact in developed countries may set in motion positive impacts in less developed countries (Das and Hilgenstock 2018: 22-23). There is a counterargument that production that had shifted out of developed countries because of rising labour costs is now shifting back because automation has reduced costs (Cortes and Morris 2020). Although this could set up counteracting forces, we do not explore these arguments. Although these effects are part of global automation, they are not a consequence of automation in South Africa.

As should be clear from the above narrative, our paper relates to the large and growing literature on the labour market implications of new technologies. Our narrative and the modelling approach we adopt are influenced by the task-based approach to production, and particularly expositions by Daron Acemoglu and David Autor and their co-authors (Acemoglu and Autor 2011; Acemoglu and Restrepo 2018, 2019; Autor 2013, 2019; Autor and Dorn 2013; Autor and Salomons 2018; Autor et al. 2003). The European Foundation for the Improvement of Living and Working Conditions presents a discussion and application (Eurofound 2016), and Arntz et al. (2016) provide an example of why a task-based approach matters.

Although this paper is influenced by this task-based literature, we do not model a thorough-going task-based approach. Rather, we use the earliest formulations, as in Autor et al. (2003) and 
Acemoglu and Autor (2011). These classify occupations into tasks by their dominant task rather than measuring labour inputs by their task content directly. We adopt the older approach because of empirical problems related to measuring task content in South Africa. We discuss these problems, as well as some of the theoretical issues related to the task approach, in Appendix A.

The approach we adopt opens us to the same criticisms as levelled at the earliest formulations in the literature. The main criticism is that by mapping whole (one-digit) occupations to broad task categories, the founding literature on automation overstated the labour-displacing effects of the new technologies, since in practice only some tasks carried out within an occupation were subject to automation. This is the essence of the criticism raised by Oesch and Piccitto (2019).

However, this criticism is essentially an empirical one, questioning the extent of displacement. Although our paper uses an empirical model, it does not provide a forecast of the likely extent of polarization in South Africa, but rather examines some scenarios to explore what factors might determine the importance of polarization in the future. ${ }^{8}$

Studies building on the founding literature, often by the same authors, also modified the initially large displacement effects by recognizing potential countervailing forces. The consensus at present seems to be that new technology can be labour-displacing, but it also induces countervailing effects that offset it. This is captured pithily in the title of Acemoglu and Restrepo's 2019 paper: 'Automation and New Tasks: How Technology Displaces and Reinstates Labor' (Acemoglu and Restrepo 2019). Autor and Salomons (2018) write: 'Many technological innovations replace workers with machines, but this capital-labor substitution need not reduce aggregate labor demand because it simultaneously induces four countervailing responses: own-industry output effects; cross-industry input-output effects; between-industry shifts; and final demand effects.' Similarly, Caselli and Manning (2019) argue that 'new technology is unlikely to cause wages for all workers to fall and will cause average wages to rise if the prices of investment goods fall relative to consumer goods (a condition supported by the data)'.

In this paper we distinguish the offsetting effects arising endogenously because of automation from those generated by other forces. David Autor is most likely right when he says that human greed will continue to provide an engine for growing demand that will counter the negative effects of automation on employment (Autor 2016). But in this paper, we are not interested in that effect, since it is not an impact of automation. We are interested in new jobs created directly or indirectly by automation, the conditions under which this will happen, and the nature of the jobs created.

There have been a number of recent papers questioning whether automation has the effects identified in the polarization literature. Klenert et al. (2020) find that robot use is linked to an increase in aggregate employment and that there is no evidence of robots reducing the share of low-skill workers across Europe. Mishel and Bivens (2017) also dispute the evidence that automation leads to overall joblessness and argue that the debate distracts attention from more urgent and immediate problems in US labour markets. Oesch and Piccitto argue that the polarization thesis

fundamentally contrasts with the European experience of the past 40 years where technology constantly increased the demand for high-skilled staff at the expense of low-skilled personnel, where the onset of globalization shifted labour-intensive

\footnotetext{
${ }^{8}$ We briefly compared our classification of employment with a more nuanced mapping of occupations used by (Bhorat et al. 2020) and found it made little difference.
} 
mass production from the North to the South, and where educational expansion massively augmented the supply of mid- and highly qualified workers. (Oesch and Piccitto 2019: 442)

Our reading of these papers is that it is important to be clear about what is meant by polarization. In particular, we can make a distinction between relative and absolute polarization. When it is argued that automation will lead to joblessness, it often appears to be interpreted as meaning that the total number of jobs in the economy will decline. The literature seems to argue that this would be an extreme view of the effects of automation. But relative polarization is not inconsistent with growing jobs for routine labour.

Davies and van Seventer (2020) offer an accounting decomposition of labour market changes in South Africa between 1993 and 2017. It was emphasized that such decompositions do not show causality. They also found that while there has been some polarization, it is rather mild. It was suggested that this is because technology in South Africa lags trends elsewhere. In this paper we examine the implications of South Africa catching up with the global trends.

\section{$3 \quad$ Model}

We model the economy-wide impacts of automation in a static computable general equilibrium (CGE) model. The model is a variant of the International Food Policy Institute (IFPRI) Standard Model. The basic model is described by (Lofgren et al. 2002). We implement it using a 2016 social accounting matrix (SAM) with a particular focus on labour market disaggregation in which twodigit and one-digit South African Standard Classification of Occupations (SASCO) occupations are identified (van Seventer and Davies 2019).

We assume a single household, thus repressing effects from changing the size distribution of income. We can therefore investigate only the functional distribution of income.

There are two key adaptations for this study. On the data side, labour is specified as 'abstract', 'routine', and 'manual', as in Davies and van Seventer (2020), while capital is disaggregated into 'equipment' and 'other capital'. On the modelling side, we represent production as a nested constant elasticity of substitution (CES) function (see Figure 1).

The results in different scenarios depend crucially upon the production set-up adopted. In particular, the results are driven in large measure by the properties of the nested CES production function and the calibrated parameters. The function is widely used in both microeconomic and macroeconomic modelling, and its properties are generally well known. We therefore highlight only the salient features here, leaving a more detailed discussion to Appendix B.

In each sector (we drop the sector index for simplicity), routine labour, $R$, and equipment, $E$, are combined in a CES aggregator to produce the composite routine factor, $F$ :

$$
Q_{F}=\alpha_{F} \cdot\left[\sum_{n} \delta_{n} \cdot\left(A_{n} \cdot Q_{n}\right)^{-\rho_{F}}\right]^{-\frac{1}{\rho_{F}}} \quad n=R, E
$$

where: 
$Q_{F}$ is the quantity of the composite routine factor;

$Q_{n}$ is the quantity of input $n=R, E$;

$\alpha_{F}$ is a shift parameter;

$\delta_{F}\left[0 \leq \delta_{n} \leq 1 ; \quad \sum_{n} \delta_{n}=1\right]$ is a distributional parameter;

$A_{n}\left[0<A_{n}\right]$ is a factor-specific productivity parameter; and

$\rho_{F}\left[-1<\rho_{F} \leq \infty ; \rho_{F} \neq 0\right]$ is a substitution parameter whose value is given by $\rho_{F}=\frac{1}{\sigma_{F}}-1$,

where $\sigma_{F}$ is the elasticity of substitution (EOS). This is the intra-routine EOS.

This is then combined at a higher level with the other two types of labour and other capital to produce the sector's value added, $Y$ :

$$
Y=\alpha \cdot\left[\sum_{f} \delta_{f} \cdot\left(A_{f} \cdot Q_{f}\right)^{-\rho}\right]^{-\frac{1}{\rho}} \quad f=A, M, K, F
$$

in which $A$ represents abstract labour, $M$ manual labour, and $K$ other capital.

In the full CGE model there is a further level of nesting: value added is combined with intermediates as a Leontief production function to produce gross output (see Figure 1).

Figure 1: The model production set-up

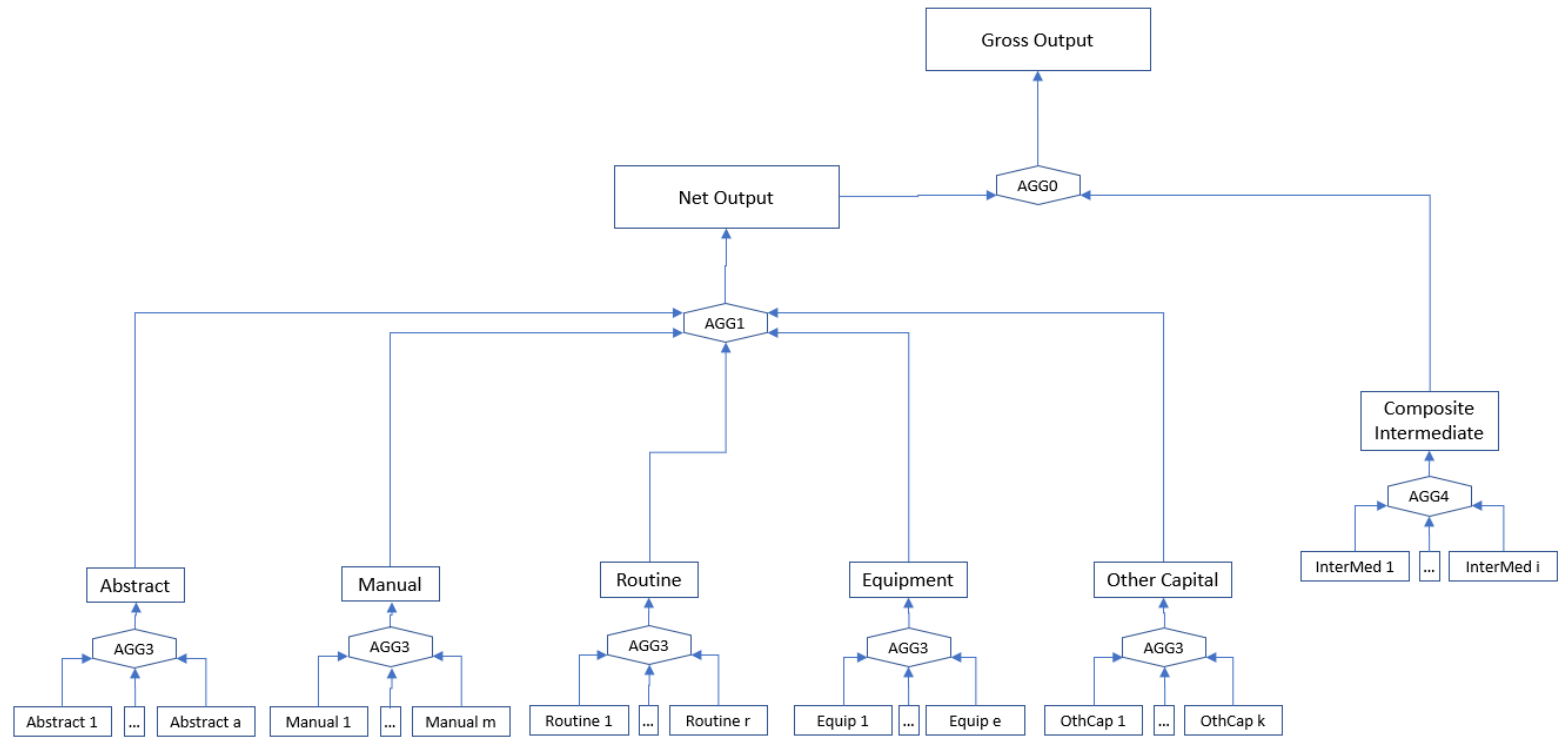

Source: authors' construction.

The behaviour of the model depends crucially on the parameters of this nested production system and particularly the elasticities of substitution. Although there have been estimates of CES production functions for South Africa (Kreuser et al. 2015), they do not fit our nested set-up. We therefore use a calibrated model. 
The production system is calibrated to be consistent with the underlying SAM for South Africa. Value added and factor inputs for each sector are taken straight from the SAM. ${ }^{9}$

There are four parameters in the CES function. We set the factor-specific productivity equal to 1 in the calibration. We obtain EOS $(\sigma)$ values from outside sources or by assumption. That allows $\rho$ to be determined. We then use the first-order optimization conditions to back out the $\delta$. We can then calculate the $a$ that is consistent with the base data, the assumed $\rho$ (or $\sigma$ ), and the consistent $\delta .^{10}$

In some of the simulations we explore the implications of different EOS. When we do so, we recalibrate the functions appropriately to derive consistent $a$ and $\delta$.

The two key elasticities are the EOS in the routine factor composite aggregation (the intra-routine EOS) and the EOS between the routine factor and other factors in producing the sector's output.

The intra-routine EOS between routine labour and equipment in the aggregation of the composite routine factor is clearly a key driver in the initial impact of automation. If no substitution were possible, labour would not be displaced by automation.

We have no information about this elasticity for South Africa or indeed other countries. Most studies assume that the two are highly substitutable. There is little impact if they are not. In some models, such as that of Acemoglu and Restrepo (2018), machines are assumed to be perfectly substitutable with routine labour. We assume rather that they are highly but not perfectly substitutable. Since we deal with aggregates in the data, which will be contaminated by elements that are unaffected by automation, it seems reasonable to assume imperfect substitution. We explored the effects of these elasticities and found that for most purposes once the elasticity reaches 5 the marginal effect of raising it further is small.

The EOS between the routine factor and other factors in the production of the sector's output also influences the extent to which automation displaces routine labour. When equipment substitutes for routine labour in the routine composite, it not only displaces labour, but also reduces the cost of the routine factor. In effect this is the same in the higher-level CES as when any factor input's price falls. If there is high substitutability, then the CES shifts towards the routine factor. This can offset the substitution that has happened at the lower level. The demand for routine labour is reduced because equipment is cheaper, but it is increased because the demand for routine factor has gone up.

As mentioned above, there are estimates for South Africa of standard CES production functions with capital and labour (e.g. Kreuser et al. 2015). However, we have no idea whether the elasticities of substitution between capital and labour carry over into elasticities of substitution between the routine factor and abstract, manual labour and other capital.

We assume that the elasticities are low (0.3), so that the routine factor is a complement to the other inputs. This makes logical sense: if the routine factor substitutes for one of the other types of

\footnotetext{
${ }^{9}$ The SAM shows the value of factor inputs into each sector. We use data on physical inputs to back out the implied factor prices.

${ }^{10}$ The issue of some parameters in the CES depending on the values of others, and its implication for their estimation, is discussed by Klump et al. (2012).
} 
labour, then that type of labour should probably have been classified as routine in the first place. In our set-up we are effectively classifying labour as routine based on whether it can be replaced by equipment.

On top of these two central elasticities, in a general equilibrium setting, introducing machines changes the distribution of income and relative prices of goods. Both of these can affect the sectoral composition of demand. How it does so will depend on the income and price elasticities of demand. We do not explore this as it requires a SAM framework with household income distribution rather than only the functional distribution of income that we have at our disposal for this study.

The properties of the nested CES production system, particularly the interaction between the intraroutine EOS and the high-level EOS, can be worked out analytically. Here we use the numerical models to illustrate how different elasticities influence the outcomes. As is obvious, in the economy the consequences of these elasticities work themselves out in a framework in which other influences and constraints matter. The implications of the elasticities may be constrained or enhanced by, for example, the availability of other factors. Policy makers have little influence over the elasticities, but they can influence the context in which automation is evolving to be more polarizing or less. It is those drivers with which we are mainly concerned.

\section{Scenarios}

We use the model to run a series of scenarios that explore some key determinants of how polarization might unfold in South Africa. We see these as indicators of where further research is needed to examine what the likely paths will be. In all scenarios, automation is represented by sectors using more equipment. The main shock imposed on the model is an increase in the supply of equipment in the economy.

In general, new technology is adopted because it is cheaper. However, there are potential nonprice reasons for adopting new technology which probably operate in most countries but might be relatively more important in South Africa than elsewhere. Foremost among these is that managing machines may be easier than managing people, especially where trade unions and labour regulations are strong. ${ }^{11}$ Furthermore, if technology in South Africa is largely embedded in imported equipment there may be little choice. For some products, even if there is a choice, the technology changes the nature of the product and the new product is perceived as being of better quality than those produced by the older technology. Firms are effectively forced into adoption simply to keep their markets. ${ }^{12}$

\footnotetext{
${ }^{11}$ The recent COVID-19 pandemic has given rise to suggestions that it will speed up adoption of the new technologies; machines do not have to self-isolate (Chernoff and Warman 2020).

${ }^{12}$ An example of this is automated apple picking leading to changes in fruit appearance (e.g. darker colours) to enable the machine to identify ripe fruit. This induces changes in consumer preferences.
} 
Whatever the reason, it is possible that automation is adopted not simply for price reasons. ${ }^{13}$ Our modelling strategy simply increases the quantity of equipment exogenously in an economy-wide setting, which causes a fall in the price of equipment. ${ }^{14}$

\subsection{Partial equilibrium}

To understand the general equilibrium effects, it is useful to run a partial equilibrium model in which the impact of an automation shock on a selected sector depends on the characteristics of the sector itself and not on any general equilibrium constraints and feedbacks. We constructed such a model comprising the nested production system outlined above plus the associated firstorder conditions. We calibrated this on the same data as the general equilibrium model and ran several simulations under different conditions. We can compare these outcomes with those of the same shock in a general equilibrium setting.

Some assumptions have to be made within the partial equilibrium setting as to which inputs are fixed and whether output is fixed or flexible. Here we provide the results of four simulations that differ in these assumptions. The four simulations were selected in order to provide the comparison with what happens in the general equilibrium setting.

\section{Simulations and results}

Table 1 shows the main results of some partial equilibrium simulations. In all simulations the shock is a 45.5 per cent increase in equipment used in the fabricated metal products sector. The sector was chosen because its output is relatively high, which means impacts in the general equilibrium setting should have discernible effects. The shock was chosen to replicate the shock to which it will be compared in the general equilibrium model.

Table 1: Partial equilibrium simulation results (\%)

\begin{tabular}{|c|c|c|c|c|c|c|c|c|c|}
\hline & & \multicolumn{2}{|c|}{ Sim 1} & \multicolumn{2}{|c|}{$\operatorname{Sim} 2$} & \multicolumn{2}{|c|}{$\operatorname{Sim} 3$} & \multicolumn{2}{|c|}{$\operatorname{Sim} 4$} \\
\hline & & $\begin{array}{l}\text { Quantity } \\
\text { (1) }\end{array}$ & $\begin{array}{l}\text { Price } \\
\text { (2) }\end{array}$ & $\begin{array}{l}\text { Quantity } \\
\text { (3) }\end{array}$ & $\begin{array}{l}\text { Price } \\
\text { (4) }\end{array}$ & $\begin{array}{l}\text { Quantity } \\
\text { (5) }\end{array}$ & $\begin{array}{l}\text { Price } \\
(6)\end{array}$ & $\begin{array}{l}\text { Quantity } \\
\text { (7) }\end{array}$ & $\begin{array}{l}\text { Price } \\
\text { (8) }\end{array}$ \\
\hline 1 & Machinery & 45.5 & 0.0 & 45.5 & -8.0 & 45.5 & -7.0 & 45.5 & -7.9 \\
\hline 2 & Routine labour & 45.5 & 0.0 & -4.1 & 0.0 & 1.1 & 0.0 & -3.6 & 0.0 \\
\hline 3 & $\begin{array}{l}\text { Composite routine } \\
\text { factor }\end{array}$ & 45.5 & 0.0 & 0.1 & -0.9 & 4.9 & -0.7 & 0.6 & -0.8 \\
\hline 4 & Other capital & 45.5 & 0.0 & -0.2 & 0.0 & 0.0 & 16.5 & 0.0 & 1.3 \\
\hline 5 & Abstract labour & 45.5 & 0.0 & -0.2 & 0.0 & 4.7 & 0.0 & 0.0 & 1.3 \\
\hline 6 & Manual labour & 45.5 & 0.0 & -0.2 & 0.0 & 4.7 & 0.0 & 0.0 & 1.3 \\
\hline 7 & Output & 45.5 & 0.0 & 0.0 & -0.5 & 4.7 & 0.0 & 0.4 & 0.0 \\
\hline
\end{tabular}

Note: $\operatorname{sim} 1$ : all factors and output flexible; $\operatorname{sim} 2$ : all factors flexible, output fixed; $\operatorname{sim} 3$ : abstract and manual labour flexible, output flexible, other capital fixed; $\operatorname{sim} 4$ : output flexible, abstract and manual labour and other capital fixed.

\footnotetext{
${ }^{13}$ Of course, all of these non-price considerations could be turned into some price equivalence: how much are managers willing to pay (in terms of foregone returns) for a quiet life?

${ }^{14}$ As a test, we also modelled the effects of exogenously reducing the price of equipment by the same amount as the fall generated endogenously by the quantity shock. As expected, it produced the same results.
} 
The simulations differ in the assumptions made about what is fixed and what is flexible. Equipment is exogenous throughout, so we that can shock it, and routine labour is flexible since our main interest is the consequence for routine labour of adopting more equipment. When the quantity of any variable is fixed, its price is made flexible.

Simulation 1: all inputs and output flexible. In simulation 1, all other factor inputs and the commodity output are flexible (and their prices are fixed). The results are unsurprising. Since we assume the production function shows constant returns to scale and is homothetic, everything expands in the same proportion. The firm is exogenously given more equipment to work with and, since it can adjust other inputs and output so as to optimize, it simply expands everything in proportion. We see in this case that increasing equipment stimulates demand for routine labour, despite equipment and routine labour being substitutes in the aggregation function.

Simulation 2: all inputs flexible and output fixed. In simulation 2, we constrain the firm's output. This completely reverses the previous results. The firm has to absorb the exogenously imposed increase in equipment. It cannot do this by expanding output. It will only absorb this equipment if the (shadow) price of equipment falls. This leads it to substitute away from routine labour $(-4.1$ per cent). In effect this reduces the implicit shadow price of the routine factor $(-0.9$ per cent). This leads to the firm substituting the routine factor for both abstract and manual labour in the higher-level output production function $(-0.2$ per cent). In addition, the cost of the output falls.

Thus, when automation occurs and the firm does not (or cannot) expand its output, it simply shifts to a lower-cost technique of production ( -0.5 per cent). We will see that this is important in the general equilibrium setting.

Simulation 3: output and labour are flexible, other capital is fixed. This simulation represents the typical short-run model of Econ 101 textbooks-fixed capital stock, flexible labour, and perfectly elastic output demand. Even though the shadow price of the routine factor falls by less than it did in simulation 2 ( -0.7 per cent vs -0.9 per cent), the use of the routine factor rises more (4.9 per cent vs 0.1 per cent), since the output of the firm can expand. The output effects dominate the substitution effects and the demand for routine labour is stimulated by the exogenous injection of equipment.

Simulation 4: output is flexible, capital, abstract labour, and manual labour are fixed. Under this simulation, although the firm faces a perfectly elastic demand for its output, the inputs into the higher-level output production are constrained. There is some additional output produced because the additional equipment reduces the shadow price of the routine factor. But absent additional abstract and manual labour, there is little additional use for the routine factor. This feeds back into the routine factor aggregation, with a large substitution away from routine labour.

\section{Lessons from the partial equilibrium analysis}

The above simulations emphasize the importance of output effects offsetting the displacing effects of automation. They show that a key determinant of whether the additional equipment, representing automation, displaces routine labour or not is whether the output of the good they are involved in producing rises or not. Inability to expand output potentially comes from two sources. There may be insufficient demand (as in simulation 2) or other inputs that are complementary to the routine factor may be constrained (as in simulation 4). 
We have provided results for simulations based on one sector. Whether these observations apply to other sectors will depend on their characteristics.

The main differences between the partial equilibrium and general equilibrium settings is that in the latter the firm may not be able to obtain other inputs without constraint or to sell its output without limit. It may have to compete with other firms for inputs. Although there are underlying assumptions of perfect competition, in the CGE model we deal with the industry and a representative firm. Any extra output of the industry has to compete with other industries for its share of aggregate demand. Although aggregate demand may be stimulated by the adoption of the new equipment in the target sector, the effect is likely to be small. It will also depend on the nature of the industry: where it sells its output and its linkages.

\subsection{General equilibrium}

Automation does not occur randomly across sectors - the possibility of automation in a particular sector will depend upon the suitability of the sector. Determining whether automating technology is appropriate for the sector, and what the specific determinants of adoption are (i.e. the supply of and demand for automation in specific sectors), would require detailed microeconomic studies. However, at the broad level of the economy-wide modelling we are undertaking here, we have to decide how the additional supply of equipment, by which we are simulating automation, is spread across the various sectors.

We adopt two strategies. The first is to let the market, as represented in our model, decide. We increase the total supply of equipment, which brings down its price, and restore equilibrium by letting the sectors compete for it. The second strategy is to allocate the equipment to targeted sectors. Within this second approach, we select the targeted sectors on a range of criteria designed to give us insight into the determinants of the impacts of automation.

The two different criteria used are, first, the susceptibility of sectors to, and their scope for, automation, and, second, sectors' linkages to the rest of the economy.

Selecting sectors based on susceptibility and scope

Although we are modelling hypothetical scenarios and not making forecasts, it would be useful if the sectors automating in the model reflected the same sectors that are likely to automate in practice. However, we have little guidance on which sectors those might be in South Africa. We therefore draw on work elsewhere and some theoretical considerations.

The possibility of automating in a sector can be thought of as depending on two different influences. First, are the occupations in the sector themselves susceptible to being automated? Second, how many people are employed in susceptible occupations within the sector? Intuitively, if there is little routine labour employed in the sector, there is little scope for replacing labour by equipment, even if it is technically highly possible.

There have been several studies of susceptibility internationally, although they focus on which occupations are at risk rather than which sectors (see Arntz et al. 2016, 2017; Frey and Osborne 2013).

Frey and Osborne solicited expert opinion on the likelihood that automated technology will be developed over the next few decades that will be able to undertake tasks currently undertaken by humans. They then constructed probabilities that occupations will be automated. We use these 
probabilities to construct an index of sectoral susceptibility for South Africa based on the risks to occupations in the sector, weighted by the share of the occupation in the sector.

With this in mind, we identified susceptible sectors as follows:

- We matched Frey and Osborne's probabilities to the four-digit occupations in the SASCO (Statistics South Africa 2012). We used the same cut-off points as Frey and Osborne to classify each four-digit occupation into low (prob $=0-0.3$ ), medium $(0.3-0.7)$, and high risk (>0.7). This gave some measure of susceptibility of occupations in South Africa.

- We then weighted these occupational susceptibilities by the share of each four-digit occupation in employment in each sector (derived from labour market dynamics (LMD; Statistics South Africa 2018)). This gave us a measure of the susceptibility of sectors.

However, simply because sectors have susceptible occupations does not mean they have the scope to automate. We measure the scope for automation by the share of routine labour in the composite routine factor for each sector. The higher this share, the greater the possibility of equipment displacing labour, ceteris paribus. ${ }^{15}$

We could explore sector targeting based on each of these measures separately. However, it is more compact to combine them, which we do. The classification of sectors is then as presented in Table 2. Table B1 in the Appendix shows the number of routine workers in each category.

\section{Selecting sectors based on their linkages to the rest of the economy}

The economy-wide effects of automation in a sector will depend in large measure on how it is linked to the rest of the economy. Since one of the effects is to raise productivity and therefore permit more output and/or lower costs, the forward linkages will be important for passing on any productivity-increasing or cost-reducing effects. Backward linkages are important for passing any demand/output-increasing effects.

As an illustration, consider what happens when productivity improves in a sector that supplies its output to other industries as an input into their production. This can, under the right circumstances, allow the receiving firm to produce more or lower its costs. Producing more raises demand for other inputs from other sectors, which has further stimulating repercussions for the economy. On the other hand, if the automating industry supplies consumer goods to households, while households benefit from lower prices and may demand more as their real income rises, that is pretty much the end of the story. Of course, if the automating industry is supplying to an export industry, the benefits will flow out of the economy and again that is the end of the story.

\footnotetext{
${ }^{15}$ It is possible that investment in new equipment replaces old, less automated equipment, so that the degree of automation increases even if the equipment-worker ratio does not change. But we are interested in labour displacement and therefore are not concerned with upgrading equipment while leaving the equipment-worker ratio the same.

There is a question of why the share of routine labour is low already. It is possible that automation has already occurred, which runs counter to our assumption that South Africa lags behind the OECD in this regard. However, we are looking at the scope for automation going forward.
} 
Table 2: Classification of sectors by susceptibility and scope

\begin{tabular}{|c|c|c|c|}
\hline \multirow[t]{2}{*}{ Susceptibility } & \multicolumn{3}{|c|}{ Scope } \\
\hline & Low & Medium & High \\
\hline \multirow[t]{11}{*}{ Low } & A & B & C \\
\hline & Agriculture & Mining of coal and lignite & Mining of gold and uranium \\
\hline & Sale, maintenance, repair & Other mining and quarrying & ore \\
\hline & of motor vehicles & Beverages and tobacco & Mining of metal ores \\
\hline & Hotels and restaurants & Footwear & Air transport \\
\hline & Education & Radio, television, communication & \\
\hline & Sewerage and refuse & equipment and apparatus & \\
\hline & disposal & Land transport, transport via pipe & \\
\hline & $\begin{array}{l}\text { Activities of membership } \\
\text { organizations }\end{array}$ & $\begin{array}{l}\text { IInes } \\
\text { Real estate activities }\end{array}$ & \\
\hline & Other activities & Health and social work & \\
\hline & & $\begin{array}{l}\text { Non-observed, informal, non- } \\
\text { profit, households }\end{array}$ & \\
\hline \multirow[t]{12}{*}{ Medium } & D & $\mathbf{E}$ & $\mathbf{F}$ \\
\hline & $\begin{array}{l}\text { Food } \\
\text { Tanning and dressing of }\end{array}$ & $\begin{array}{l}\text { Spinning, weaving, and finishing } \\
\text { of textiles }\end{array}$ & $\begin{array}{l}\text { Nuclear fuel, basic } \\
\text { chemicals }\end{array}$ \\
\hline & leather & Machinery and equipment & Other chemical products, \\
\hline & & & $\begin{array}{l}\text { man-made fibres } \\
\text { Glass }\end{array}$ \\
\hline & Medical, precision, optical & Auxiliary transport & Electrical machinery and \\
\hline & instruments, watches and & Post and telecommunication & apparatus \\
\hline & clocks & Insurance and pension funding & Electricity, gas, steam, and \\
\hline & $\begin{array}{l}\text { Manufacturing n.e.c, } \\
\text { recycling }\end{array}$ & $\begin{array}{l}\text { Renting of machinery and } \\
\text { equipment }\end{array}$ & $\begin{array}{l}\text { hot water supply } \\
\text { Financial intermediation }\end{array}$ \\
\hline & Retail trade & Research and experimental & Activities to financial \\
\hline & Recreational, cultural and & development & intermediation \\
\hline & sporting activities & & $\begin{array}{l}\text { Computer and related } \\
\text { activities }\end{array}$ \\
\hline & & & Government \\
\hline \multirow[t]{10}{*}{ High } & G & $\mathbf{H}$ & $\mathbf{I}$ \\
\hline & Forestry & Fishing & Publishing, printing, \\
\hline & $\begin{array}{l}\text { Sawmilling, planing of } \\
\text { wood, cork, straw }\end{array}$ & $\begin{array}{l}\text { Knitted, crocheted fabrics, wearing } \\
\text { apparel, fur articles }\end{array}$ & $\begin{array}{l}\text { recorded media } \\
\text { Plastic }\end{array}$ \\
\hline & Construction & Paper & Basic precious and non- \\
\hline & Water transport & Rubber & ferrous metals \\
\hline & & Non-metallic minerals & Fabricated metal products \\
\hline & & $\begin{array}{l}\text { Basic iron and steel, casting of } \\
\text { metals }\end{array}$ & $\begin{array}{l}\text { Motor vehicles, trailers, } \\
\text { parts }\end{array}$ \\
\hline & & Furniture & Other transport equipment \\
\hline & & $\begin{array}{l}\text { Collection, purification, and } \\
\text { distribution of water }\end{array}$ & \\
\hline & & Other business activities & \\
\hline
\end{tabular}

Note: susceptibility and scope are explained in the text.

Source: authors' calculations.

To assess the relative importance of each sector's linkages in the South African economy, we converted the SAM underlying our general equilibrium analysis into an input-output table. We then estimated standard Leontief multipliers to measure backward linkages. For forward linkages we used the Ghosh method, which is based upon the supply coefficients of industries rather than their cost structure as in the standard Leontief method.

For both sets of multipliers, we followed Miller and Blair (2009: 555-60), calculating the multipliers and normalizing them so that the mean multiplier across the entire economy is equal to 1 . Finally, we classified both sets of normalized multipliers into three groups. Sectors more than 0.4 standard deviations below the mean were classed as 'low', those with normalized multipliers more than 0.4 
standard deviations above the mean were classed as 'high', and the remainder were classed as 'average'.

Table 3 shows the final cross tabulation of sectors into these groups. The impact of a sector on the economy depends not only on its linkages but also its size. Multipliers measure impact per unit. A sector may have strong forward linkages but could be small, so any increase in productivity does not have much impact. ${ }^{16}$ In Table 3, we therefore also provide data on each sector's size, as measured by its share in gross output of the economy.

Table 3: Classification of sectors by forward and backward linkages

\begin{tabular}{|c|c|c|c|c|c|c|c|}
\hline & \multicolumn{6}{|c|}{ Backward linkages } \\
\hline & & \multicolumn{2}{|l|}{ Below (39.4) } & \multicolumn{2}{|l|}{ Average (40.7) } & \multicolumn{2}{|l|}{ Above (19.9) } \\
\hline & & Sector & Size & Sector & Size & Sector & Size \\
\hline \multirow{24}{*}{ 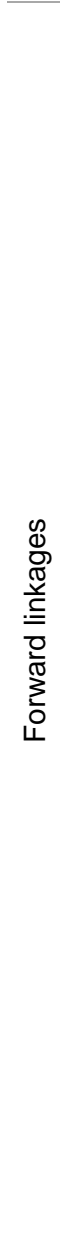 } & \multirow[t]{11}{*}{$\begin{array}{l}\text { Below } \\
(41.9)\end{array}$} & Agriculture & 2.2 & $\begin{array}{l}\text { Other mining and } \\
\text { quarrying }\end{array}$ & 1.6 & Food & 3.7 \\
\hline & & Fishing & 0.1 & Beverages and tobacco & 1.1 & Clothing & 0.4 \\
\hline & & Mining of metal ores & 3.9 & Footwear & 0.1 & Leather & 0.1 \\
\hline & & Government & 10.7 & Machinery & 1.2 & Furniture & 0.2 \\
\hline & & & & Instruments & 0.1 & & \\
\hline & & & & Motor vehicles & 2.1 & & \\
\hline & & & & Other transport equipment & 0.2 & & \\
\hline & & & & Construction & 5.3 & & \\
\hline & & & & $\begin{array}{l}\text { Insurance and pension } \\
\text { funding }\end{array}$ & 1.9 & & \\
\hline & & & & Real estate activities & 4.9 & & \\
\hline & & & & Health \& social work & 1.9 & & \\
\hline & \multirow{6}{*}{$\begin{array}{l}\text { Average } \\
(20.9)\end{array}$} & Mining of coal & 1.2 & Basic chemicals & 1.4 & Textiles & 0.4 \\
\hline & & Petroleum & 1.9 & Glass & 0.1 & Other chemicals & 1.8 \\
\hline & & Manufacturing n.e.c. & 0.7 & Hotels and restaurants & 1.1 & Basic iron \& steel & 1.8 \\
\hline & & Electricity & 2.2 & Education & 1.0 & Non-ferrous metals & 0.7 \\
\hline & & Transport & 5.2 & & & Electrical machinery & 0.5 \\
\hline & & & & & & $\begin{array}{l}\text { Research and } \\
\text { development }\end{array}$ & 0.7 \\
\hline & \multirow{7}{*}{$\begin{array}{l}\text { Above } \\
(37.2)\end{array}$} & Forestry & 0.2 & Wood & 0.6 & Paper & 1.0 \\
\hline & & Non-metallic minerals & 0.5 & Rubber & 0.2 & Printing & 0.6 \\
\hline & & Auxiliary transport & 1.0 & Plastic & 0.5 & Fabricated metal products & 1.1 \\
\hline & & $\begin{array}{l}\text { Financial } \\
\text { intermediation }\end{array}$ & 3.6 & Water & 0.8 & Radio, TV, apparatus & 0.4 \\
\hline & & Other services & 6.0 & Trade & 9.8 & $\begin{array}{l}\text { Renting machinery and } \\
\text { equipment }\end{array}$ & 1.4 \\
\hline & & & & $\begin{array}{l}\text { Post and } \\
\text { telecommunication }\end{array}$ & 2.2 & Other business activities & 4.9 \\
\hline & & & & Financial intermediation & 2.4 & & \\
\hline
\end{tabular}

Note: size is measured as the percentage share in total value of gross output

Source: authors' calculations

16 This is always a problem with multiplier analysis. We really want something which captures both size and the linkages. The main method for doing this these days is the hypothetical extraction method which assesses how the economy would perform if a sector were missing. We have not used that here. 


\subsection{Results of market-driven scenarios}

To get our bearings, it is useful to look at the impacts when the (exogenous) increase in the economy-wide supply of equipment is allocated to sectors through the market. Profit-maximizing adjustments built into a standard CGE model lead to those sectors most able to benefit from the additional equipment expanding their stock more than those less able to benefit. This mechanism leads to the most efficient allocation of the increase in equipment. Table 4 shows the results for two simulations under this scenario. In both simulations the stock of other capital (i.e. nonequipment capital) in each sector is fixed. In simulation 1 the economy-wide supplies of abstract and manual labour are fixed, but both are free to move between sectors in response to sectoral demands. In simulation 4 , both of these types of labour are supplied to the economy perfectly elastically.

Table 4: Market-driven outcomes on factor supplies and incomes with fixed and flexible supplies of other labour

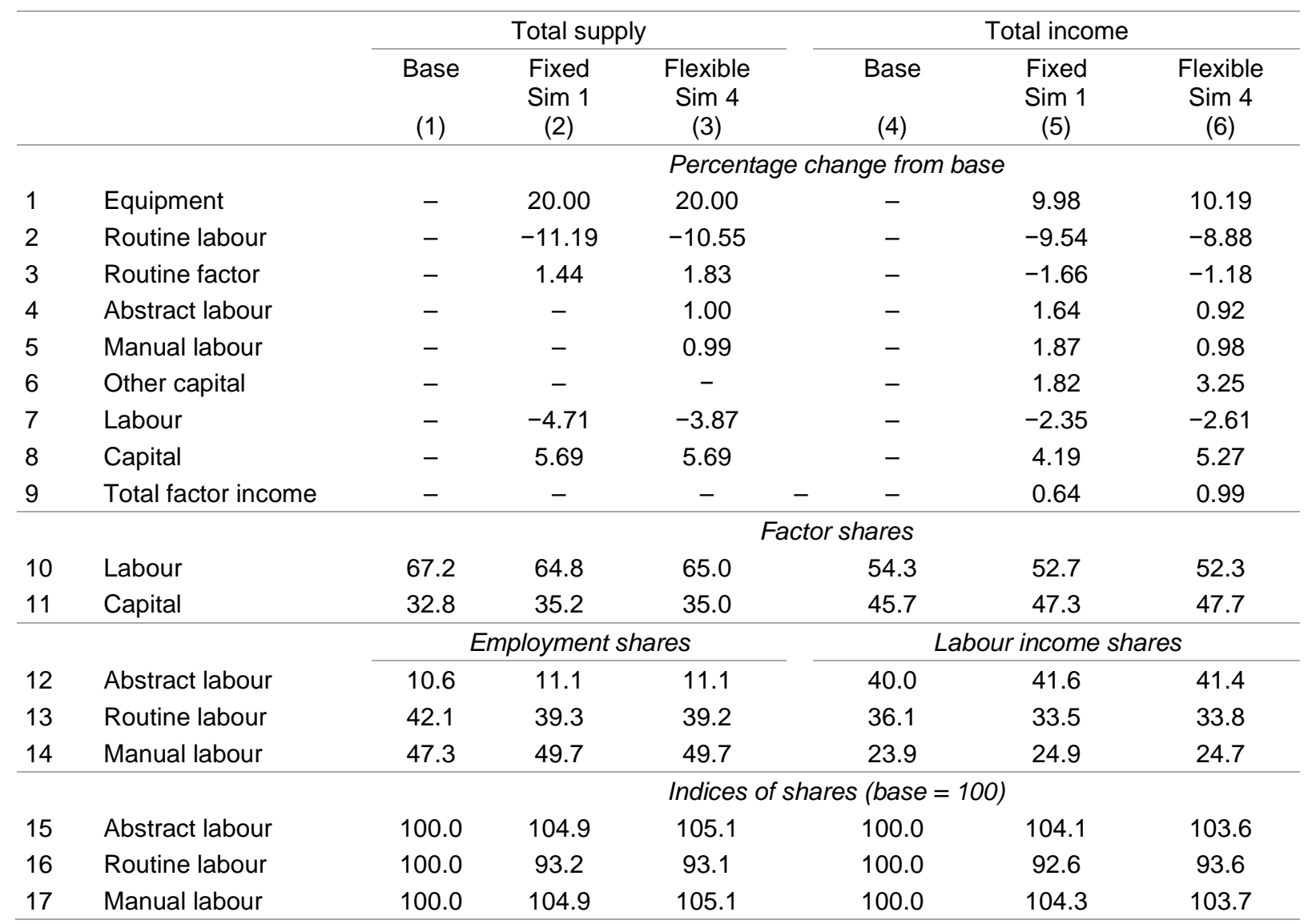

Note: 'fixed' means the total supply of abstract and manual labour are fixed; 'flexible' means the total supplies of abstract and manual labour are flexible.

Source: authors' calculations

Thus, in simulation 1, if a sector's demand for abstract or manual labour rises in response to having access to more equipment and routine factor, it has to attract already-employed labour from other sectors. Their economy-wide wage rates will rise. There will be a reallocation of labour between sectors, but the aggregate economy-wide demand for them does not change. The reallocation reflects increases in some sectors and decreases in others. 
In simulation 4, the firm can acquire the additional abstract and manual labour it demands without pulling it from already-employed labour in other sectors. Wage rates will not change. The sectoral pattern of use of labour may change, but only because some sectors create more jobs than others, not because they lose out in the competition for the scarce abstract and manual labour.

Table 4 shows the impact on the quantities of each factor and their incomes of increasing equipment in the economy by 20 per cent. Recall from the earlier partial equilibrium analysis that the constant return to scale properties of the production system mean that if all sectors were unconstrained in both their inputs and the output they could sell, we would expect everything to expand by 20 per cent. It does not do so here for several reasons. Stocks of non-equipment capital are fixed in each sector. Output expansion is constrained by the need to sell it and demand has not increased, save for the small stimulus from the injection of equipment. Row 9 shows that total factor income rises by under 1 per cent. The demand created by the injection of equipment is insufficient to create the demand needed to absorb the output it could produce.

We see, as expected, that equipment displaces routine labour (row 2). The displacement is less when the supplies of abstract and manual labour are flexible (column 3). This is what we expect and has some rather obvious policy implications. To reduce the labour-displacing effects of automation it is important to ensure that there are adequate supplies of complementary labour. Indeed, this is a special instance of a more general consideration for creating jobs in South Africa. A shortage of one type of labour leads to less employment for other types.

These impacts on quantities have implications for incomes. The total income of routine labour is reduced by the injection of equipment. This is no surprise, being driven by the large displacement. However, note that the incomes accruing to abstract and manual labour rise, and rise by more when their supply is constrained than when it is not. The injection of equipment raises the demand for these types of labour. If the supply is unable to respond, their wages rise. A scarce factor can earn a scarcity premium. When demand for it rises, making it even more scarce, the scarcity premium rises. Again, this is a particular instance of the more general phenomenon in South Africa. Those employees with scarce skills benefit more from a growing economy, than those whose skills are in plentiful supply. This applies more for manual labour than for abstract labour, although the former is in the South African economic reality less likely to be supply-constrained.

The growth impacts noted above point to the drivers of polarization. The polarization caused by the injection of equipment is shown in several ways in Table 4. Rows 12-14 show how the shares in employment and labour income are affected by the injection of equipment. In both cases the share of routine labour falls. There is thus polarization of both employment and incomes. This is relatively unaffected by whether the complementary labour is in fixed or flexible supply.

Earlier we suggested that polarization can be viewed as an absolute or a relative phenomenon, whether with respect to jobs or to incomes. In our static model there is little scope for considering absolute polarization, since there is no growth. However, looking at the change from the base in row 2 of Table 4, we can see that the displacement of routine labour is less when the complementary labour is flexible $(-10.55$ per cent $)$ than when it is not $(-11.19$ per cent). Thus, in absolute terms, the flexible scenario is better for routine labour than the fixed one. However, in relative terms, polarization of employment is greater when the complementary labour is flexible. This can be seen in rows 15-17 of the table. Compared to their shares of employment in the base, not only does routine labour's share fall more, but both abstract and manual labour's shares rise. The flexibility not only mitigates the displacement effects on routine labour, but creates jobs for the other two labour types. 
Recall that automation not only has substitution effects within the aggregator that creates the composite routine factor out of routine labour and equipment, but also has cost-reducing effects. These can lead to output effects that counter the initial substitution. As we illustrated in the partial equilibrium analysis, the counterbalancing output effects will be greater the more the complementary inputs are able to expand. That reduces the loss of routine jobs, but it is possible, as in this instance, that their expansion exacerbates the relative polarizing effects.

However, the relative polarization of incomes is reduced by the flexibility of the complementary labour inputs. This is shown in the last two columns of rows 15-17 in Table 4. When abstract and manual labour are in fixed total supply, the increased demand for them induced by the falling cost of routine tasks simply pushes up their wages. When the supplies can expand, this does not happen.

In this scenario we then find a mix of results. There is polarization, since our model is calibrated to show that, but ability to increase inputs of abstract and manual labour worsens relative jobs polarization while reducing relative income polarization.

In common with the literature, we have focused on polarization within the labour market. Concern with the impact of automation on income distribution would lead us to look also at its impact on capital income. As noted earlier, we cannot explore the household distribution of income since our SAM has only one household. But Table 4 shows that the functional distribution shifts towards capital when new equipment is injected (rows 10 and 11). Since we know that in South Africa income from capital and from abstract labour is skewed towards upper-income households, we might infer that automation will increase the already high income inequality.

\subsection{Results of targeted simulations}

The results of the simulations targeting sectors selected on susceptibility and scope are shown in Table 5, and those targeting sectors selected on linkages are given in Table 6. 
Table 5: Increases in equipment in sectors selected by susceptibility and scope

\begin{tabular}{|c|c|c|c|c|c|c|}
\hline & \multicolumn{3}{|c|}{ Total supply } & \multicolumn{3}{|c|}{ Total income } \\
\hline & Base & $\begin{array}{l}\text { Fixed } \\
\text { Sim } 1\end{array}$ & $\begin{array}{c}\text { Flexible } \\
\text { Sim } 4\end{array}$ & Base & $\begin{array}{l}\text { Fixed } \\
\text { Sim } 1\end{array}$ & $\begin{array}{c}\text { Flexible } \\
\text { Sim } 4\end{array}$ \\
\hline & \multicolumn{6}{|c|}{ Percentage change from base } \\
\hline Equipment & - & 20.00 & 20.00 & - & 7.36 & 7.60 \\
\hline Routine labour & - & -3.09 & -2.62 & - & -6.80 & -6.33 \\
\hline Routine factor & - & 0.89 & 1.16 & - & -1.08 & -0.70 \\
\hline Abstract labour & - & - & 0.73 & - & 1.25 & 0.71 \\
\hline Manual labour & - & - & 0.72 & - & 1.38 & 0.74 \\
\hline Other capital & - & - & - & - & 1.27 & 2.30 \\
\hline Labour & - & -1.30 & -0.69 & - & -1.63 & -1.83 \\
\hline Capital & - & 5.69 & 5.69 & - & 3.04 & 3.84 \\
\hline \multirow[t]{2}{*}{ Total factor income } & - & - & - & - & - & 0.76 \\
\hline & \multicolumn{6}{|c|}{ Factor shares } \\
\hline Labour & 67.2 & 65.6 & 65.8 & 54.3 & 53.1 & 52.9 \\
\hline \multirow[t]{2}{*}{ Capital } & 32.8 & 34.4 & 34.2 & 45.7 & 46.9 & 47.1 \\
\hline & \multicolumn{6}{|c|}{ Employment shares } \\
\hline Abstract labour & 10.6 & 10.7 & 10.7 & 40.0 & 41.2 & 41.0 \\
\hline Routine labour & 42.1 & 41.3 & 41.3 & 36.1 & 34.3 & 34.5 \\
\hline Manual labour & 47.3 & 48.0 & 48.0 & 23.9 & 24.6 & 24.5 \\
\hline Other capital & 28.5 & 32.3 & 32.3 & 29.1 & 30.3 & 30.1 \\
\hline \multirow[t]{2}{*}{ Routine factor } & 71.5 & 67.7 & 67.7 & 70.9 & 69.7 & 69.9 \\
\hline & \multicolumn{6}{|c|}{ Indices of shares (base $=100)$} \\
\hline Abstract labour & 100.0 & 101.3 & 101.4 & 100.0 & 102.9 & 102.6 \\
\hline Routine labour & 100.0 & 98.2 & 98.1 & 100.0 & 94.7 & 95.4 \\
\hline Manual labour & 100.0 & 101.3 & 101.4 & 100.0 & 103.1 & 102.6 \\
\hline Other capital & 100.0 & 113.5 & 113.5 & 100.0 & 104.2 & 103.6 \\
\hline Routine factor & 100.0 & 94.6 & 94.6 & 100.0 & 98.3 & 98.5 \\
\hline
\end{tabular}

Source: authors' calculations. 
Table 6: Fall in price of equipment for sectors selected on linkages

\begin{tabular}{|c|c|c|c|c|c|c|c|c|c|c|}
\hline & \multicolumn{5}{|c|}{ Total supply } & \multicolumn{5}{|c|}{ Total income } \\
\hline & \multirow[b]{2}{*}{$\begin{array}{c}\text { Base } \\
\text { (1) }\end{array}$} & \multicolumn{2}{|c|}{ Fixed } & \multicolumn{2}{|c|}{ Flexible } & \multirow[b]{2}{*}{$\begin{array}{c}\text { Base } \\
\text { (6) }\end{array}$} & \multicolumn{2}{|c|}{ Fixed } & \multicolumn{2}{|c|}{ Flexible } \\
\hline & & $\begin{array}{c}\text { High } \\
\text { linkage } \\
(2)\end{array}$ & $\begin{array}{c}\text { Low linkage } \\
\text { (3) }\end{array}$ & $\begin{array}{c}\text { High } \\
\text { linkage } \\
(4)\end{array}$ & $\begin{array}{l}\text { Low } \\
\text { linkage } \\
\text { (5) }\end{array}$ & & $\begin{array}{c}\text { High } \\
\text { linkage } \\
(7)\end{array}$ & $\begin{array}{l}\text { Low } \\
\text { linkage } \\
\text { (8) }\end{array}$ & $\begin{array}{c}\text { High } \\
\text { linkage } \\
(9)\end{array}$ & $\begin{array}{c}\text { Low } \\
\text { linkage } \\
(10)\end{array}$ \\
\hline & \multicolumn{10}{|c|}{ Percentage change from base } \\
\hline Equipment & - & 20.00 & 20.00 & 20.74 & 20.36 & - & 9.81 & 10.05 & 10.47 & 10.37 \\
\hline Routine labour & - & -14.09 & -10.10 & -13.53 & -9.83 & - & -10.11 & -9.43 & -9.45 & -9.13 \\
\hline Routine factor & - & 2.20 & 1.14 & 2.86 & 1.45 & - & -2.07 & -1.56 & -1.41 & -1.25 \\
\hline Abstract labour & - & - & - & 1.49 & 0.72 & - & 2.33 & 1.24 & 1.35 & 0.74 \\
\hline Manual labour & - & - & - & 1.55 & 0.69 & - & 2.70 & 1.43 & 1.32 & 0.86 \\
\hline Other capital & - & - & - & - & - & - & 2.35 & 1.66 & 4.60 & 2.71 \\
\hline Labour & - & -5.93 & -4.26 & -4.81 & -3.74 & - & -2.08 & -2.57 & -2.56 & -2.80 \\
\hline Capital & - & 5.69 & 5.69 & 5.91 & 5.80 & - & 4.52 & 4.10 & 6.31 & 4.93 \\
\hline \multirow[t]{2}{*}{ Total factor income } & & & & & & - & 0.94 & 0.48 & 1.50 & 0.74 \\
\hline & \multicolumn{10}{|c|}{ Factor shares } \\
\hline Labour & 67.2 & 64.5 & 65.0 & 64.8 & 65.1 & 54.3 & 52.6 & 52.6 & 52.1 & 52.4 \\
\hline \multirow[t]{2}{*}{ Capital } & 32.8 & 35.5 & 35.0 & 35.2 & 34.9 & 45.7 & 47.4 & 47.4 & 47.9 & 47.6 \\
\hline & \multicolumn{5}{|c|}{ Employment shares } & \multicolumn{5}{|c|}{ Income shares } \\
\hline Abstract labour & 10.6 & 11.2 & 11.0 & 11.3 & 11.0 & 40.0 & 41.8 & 41.6 & 41.6 & 41.5 \\
\hline Routine labour & 42.1 & 38.5 & 39.5 & 38.3 & 39.4 & 36.1 & 33.2 & 33.6 & 33.6 & 33.8 \\
\hline Manual labour & 47.3 & 50.3 & 49.4 & 50.5 & 49.5 & 23.9 & 25.0 & 24.8 & 24.8 & 24.7 \\
\hline Other capital & 28.5 & 32.3 & 32.3 & 32.5 & 32.4 & 29.1 & 30.5 & 30.7 & 30.2 & 30.6 \\
\hline \multirow[t]{2}{*}{ Routine factor } & 71.5 & 67.7 & 67.7 & 67.5 & 67.6 & 70.9 & 69.5 & 69.3 & 69.8 & 69.4 \\
\hline & \multicolumn{10}{|c|}{ Indices of shares (base $=100)$} \\
\hline Abstract labour & 100.0 & 106.3 & 104.4 & 106.6 & 104.6 & 100.0 & 104.5 & 103.9 & 104.0 & 103.6 \\
\hline Routine labour & 100.0 & 91.3 & 93.9 & 90.8 & 93.7 & 100.0 & 91.8 & 93.0 & 92.9 & 93.5 \\
\hline Manual labour & 100.0 & 106.3 & 104.4 & 106.7 & 104.6 & 100.0 & 104.9 & 104.1 & 104.0 & 103.8 \\
\hline
\end{tabular}

Source: authors' calculations. 
In the susceptibility and scope shocks, the sectors that were classified in or above the medium group for each criterion were shocked (those in cells E, F, H, and I in Table 2). This gave 32 sectors. They all received a uniform percentage increase in their stock of equipment, calibrated so that in sum there was a rise of 20 per cent in the stock of equipment in the economy.

The results show that if the additional equipment is concentrated in the industries that are more susceptible to, and have more scope for, automation, routine labour declines less than when the distribution of equipment is left to the market. Thus, when abstract and manual labour are in fixed supply, the increase in equipment targeted to these sectors leads to a fall in routine labour of 3.09 per cent, compared to the market-determined fall of 11.19 per cent shown in Table 4 . This may seem counterintuitive, since one might expect routine labour to be more negatively impacted as the distribution of equipment is biased towards industries that have more scope to substitute away from routine labour in the routine factor. However, this result appears to be because the model is not permitted to allocate equipment across the economy in an optimal way. If we permitted more flexibility, equipment would shift between sectors. We have allocated it, within the targeted sectors, in a way that keeps each sector's share of equipment in the targeted group constant. Sectors attempt to adjust to the increase not only by reducing their routine labour, but by demanding more abstract and manual labour. Given the constraints on satisfying these demands, and the constraints imposed by the need to sell their additional output, it is likely that some sectors find that their optimal outcome would be to get more equipment, while others would optimize by using less. But this reallocation is not permitted. If it were, the optimal outcome would be where even less routine labour is demanded.

The results in Table 5 thus may appear to be a modelling artefact, caused by the design of the simulation. However, this is not the case. The income of routine labour is also less negatively impacted. Also, the combination of equipment and routine labour - that is, the routine factordoes not appear to have benefited more. The price of the routine factor has dropped by less and therefore less is supplied. With less routine factor to work with, abstract and manual labour are supplied less compared to the market-based simulation and total factor income is up by relatively less. This suggests that the lower negative impact on routine labour does not seem to be the result of higher positive second-order economy-wide effects.

Turning to the scenarios targeting sectors based on their linkages, the headline result is that when the distribution of equipment is biased towards industries with high linkages, the impact of total factor income (i.e. gross domestic product) is the highest of all scenarios whether or not the supply of the other factors of production is constrained. The opposite is the case if equipment is biased towards industries with relatively low linkages. Abstract and manual labour get to work with more routine factor compared to the other scenarios. But the downside is that in the high-linkage subscenario, the loss of routine labour is also the highest. More routine labour gets substituted away in spite of the higher economy-wide impact. This suggests that, as in the case with the susceptibility/scope scenario, the second-order effects through the employment of more abstract and manual labour and higher total factor income is not enough to save all the routine labour jobs.

In both scenarios, the functional distribution of income moves towards capital to a greater or lesser extent.

\subsection{Further simulations}

The simulations reported here focus entirely on the consequences of injections of equipment into the economy. We have focused solely on the side of adoption of the new technologies and have 
assumed that the new equipment is not produced in the economy but is simply injected, as manna from heaven.

Clearly there is another side to this. The process of investing in the new technology has consequences for investment. At the same time as adopting the new technology affects the production side of the economy, it will influence the demand side through the investment required to install the new equipment. We have not modelled that aspect of the process.

However, any injection of investment demand has to be accompanied by an increase in savings. This leakage reduces the stimulative effect of the investment associated with technology adoption and makes it unlikely to be the source of the demand expansion required to counterbalance the displacement effects of automation.

\section{Conclusions}

We used a CGE model to examine labour market polarization in South Africa. We simulated the adoption of new technology in the economy by injecting equipment into it. The model set-up is such that the new equipment displaces routine labour. In that sense, polarization is built into the assumptions of the model. It is therefore not surprising that our simulations lead to polarization. Nonetheless, we can get some insights from the exercise.

The main conclusion is that the tendency towards polarization is lessened as output is able to expand. The displacement effects of the new technology can be counterbalanced by productivity effects, provided there is an outlet for the greater output that can be produced. But in all scenarios, the stimulating effects of automation's productivity enhancement are insufficient to grow the economy enough to offset its displacement effects. A key determinant of whether demand for routine labour falls is whether output can expand adequately. In the general equilibrium setting this is constrained by demand. Automation does not by itself stimulate demand sufficiently. The displacement of routine labour is not offset by any second-order economy-wide effects.

Although automation will stimulate demand through the investment that accompanies it, this stimulus will be insufficient to generate the required expansionary impetus needed to offset the displacement effects of the technology adoption, since it has to be matched by savings. Foreign investment might fill this gap. Otherwise higher demand needs to come from other sources.

This simply reiterates what has been observed at least since Ricardo considered the impact of machinery on employment: labour-displacing technologies are better adopted in growing economies. A general policy conclusion is that, in the face of automation, effective growthenhancing policies are more important than ever.

At a less macroeconomic level, an important conclusion is that the displacement effects of automation can be somewhat mitigated if the complementary inputs of abstract and manual labour can be expanded. The less the supply of other factors constrains the economy, the less polarization will occur, even though it will not be offset completely. This has important implications for labour and skills development policies.

Finally, there are clear income distribution implications. Although our model was not set up to examine the size distribution of income, all scenarios showed not only a polarization of income 
within the labour market, but also a bias towards capital income. These will exacerbate the already unacceptably unequal distribution of income in South Africa.

\section{References}

Acemoglu, D., and D.H. Autor (2011). 'Skills, Tasks and Technologies: Implications for Employment and Earnings'. In D. Card and O. Ashenfelter (eds) Handbook of Labor Economics. Amsterdam: Elsevier. https://doi.org/10.1016/S0169-7218(11)02410-5

Acemoglu, D., and P. Restrepo (2018). 'The Race Between Man and Machine: Implications of Technology for Growth, Factor Shares, and Employment'. American Economic Review, 108(6): 1488-542. https://doi.org/10.1257/aer.20160696

Acemoglu, D., and P. Restrepo (2019). 'Automation and New Tasks: How Technology Displaces and Reinstates Labor'. Journal of Economic Perspectives, 33(2): 3-30. https://doi.org/10.1257/jep.33.2.3

Arntz, M., T. Gregory, and U. Zierahn (2016). 'The Risk of Automation for Jobs in OECD Countries: A Comparative Analysis'. Social, Employment and Migration Working Paper 189. Paris: OECD Publishing.

Arntz, M., T. Gregory, and U. Zierahn (2017). Revisiting the Risk of Automation. Economics Letters, 159: 157-60. https://doi.org/10.1016/j.econlet.2017.07.001

Autor, D.H. (2013). 'The “Task Approach" to Labor Markets: An Overview'. Working Paper 18711. Cambridge, MA: NBER. https://doi.org/10.3386/w18711

Autor, D.H (2016). 'Will Automation Take Away All Our Jobs', TED Talk. Available at: www.youtube.com/watch?v=th3nnEpITz0\&ab_channel=TED (accessed 24 September 2020).

Autor, D.H (2019). 'Work of the Past, Work of the Future'. Working Paper 25588. Cambridge, MA: NBER. https://doi.org/10.3386/w25588

Autor, D.H., and D. Dorn (2013). 'The Growth of Low-Skill Service Jobs and the Polarization of the US Labor Market'. American Economic Review, 103(5): 1553-97. https:// doi.org/10.1257/aer.103.5.1553

Autor, D.H, and A. Salomons (2018). 'Is Automation Labor-Displacing? Productivity Growth, Employment, and the Labor Share'. Working Paper 24871. Cambridge, MA: NBER. https://doi.org/10.3386/w24871

Autor, D.H., F. Levy, and R.J. Murnane (2003). 'The Skill Content of Recent Technological Change: An Empirical Exploration'. The Quarterly Journal of Economics, 118(4): 1279-333. https://doi.org/10.1162/003355303322552801

Bhorat, H., K. Lilenstein, M. Oosthuizen, and A. Thornton (2020). 'Wage Polarization in a High-Inequality Emerging Economy'. WIDER Working Paper 2020/55. Helsinki: UNU-WIDER. https://doi.org/10.35188/UNU-WIDER/2020/812-2

Breemersch, K., J.P. Damijan, and J. Konings (2017). 'Labour Market Polarization in Advanced Countries: Impact of Global Value Chains, Technology, Import Competition from China and Labour Market Institutions'. Social, Employment and Migration Working Paper 197. Paris: OECD.

Caselli, F., and A. Manning (2019). 'Robot Arithmetic: New Technology and Wages'. American Economic Review: Insights. https://doi.org/10.1257/aeri.20170036

Chernoff, A.W., and C. Warman (2020). 'COVID-19 and Implications for Automation'. Working Paper 27249. Cambridge, MA: NBER. https://doi.org/10.3386/w27249

Cortes, G.M., and D.M. Morris (2020). 'Are Routine Jobs Moving South? Evidence from Changes in the Occupational Structure of Employment in the USA and Mexico'. WIDER Working Paper 2020/11. Helsinki: UNU-WIDER. https:/ / doi.org/10.35188/UNU-WIDER/2020/768-2 
Das, M., and B. Hilgenstock (2018). 'The Exposure to Routinization: Labor Market Implications for Developed and Developing Economies'. Working Paper. Washington, DC: IMF. https://doi.org/10.5089/9781484361900.001

Davies, R., and D. van Seventer (2020). 'Labour Market Polarization in South Africa: A Decomposition Analysis'. WIDER Working Paper 2020/17. Helsinki: UNU-WIDER. https://doi.org/10.35188/UNU-WIDER/2020/774-3

Elias, P. (1997). 'Occupational Classification (ISCO-88): Concepts, Methods, Reliability, Validity and CrossNational Comparability'. Labour Market and Social Policy Occasional Paper 20. Paris: OECD Publishing.

Eurofound (2016). What Do Europeans Do at Work? A Task-Based Analysis: European Jobs Monitor 2016. Luxembourg: Publications Office of the European Union.

Frey, C.B., and M.A. Osborne (2013). 'The Future of Employment: How Susceptible Are Jobs to Computerisation?'. Working Paper. Oxford: Oxford Martin Programme on Technology and Employment.

Goos, M., A. Manning, and A. Salomons (2014). 'Explaining Job Polarization: Routine-Biased Technological Change and Offshoring'. American Economic Review, 104(8): 2509-26. https://doi.org/10.1257/aer.104.8.2509

Harding, T., and J. Rattsø (2009). 'Looking Abroad, but Lagging Behind: How the World Technology Frontier Affects South Africa'. Working Paper 5/2009. Trondheim: Norwegian University of Science and Technology, Department of Economics.

Klenert, D., E. Fernández-Macías, and J.-I. Antón (2020). Do Robots Really Destroy Jobs? Evidence from Europe. Seville: European Commission.

Klump, R., P. McAdam, and A. Willman (2012). 'The Normalized CES Production Function: Theory and Empirics'. Journal of Economic Surveys, 26(5): 769-799. https://doi.org/10.1111/j.14676419.2012.00730.x

Kreuser, F., R. Burger, and N. Rankin (2015). 'The Elasticity of Substitution and Labour-Displacing Technical Change in Post-Apartheid South Africa'. WIDER Working Paper 2015/101. Helsinki: UNU-WIDER. https://doi.org/10.35188/UNU-WIDER/2015/990-9

Lofgren, H., R.L. Harris, and S. Robinson (2002). A Standard Computable General Equilibrium (CGE) Model in GAMS. Washington, DC: International Food Policy Research Institute.

Miller, R.E., and P.D. Blair (2009). Input-Output Analysis: Foundations and Extensions, 2nd ed. New York: Cambridge University Press. https://doi.org/10.1017/CBO9780511626982

Mishel, L., and J. Bivens (2017). The Zombie Robot Argument Lurches On: There Is No Evidence That Automation Leads to Joblessness or Inequality. New York: Economic Policy Institute.

Nedelkoska, L., and G. Quintini (2018). 'Automation, Skills Use and Training'. Social, Employment and Migration Working Paper 202. Paris: OECD Publishing.

Oesch, D., and G. Piccitto (2019). 'The Polarization Myth: Occupational Upgrading in Germany, Spain, Sweden, and the UK, 1992-2015'. Work and Occupations, 46(4): 441-69. https://doi.org/10.1177/0730888419860880

Parolin, Z. (2019). 'Automation and Occupational Wage Trends'. Social, Employment and Migration Working Paper 228. Paris: OECD.

Roy, A. (1951). 'Some Thoughts on the Distribution of Earnings'. Oxford Economic Papers, 3(2): 135-46. https://doi.org/10.1093/oxfordjournals.oep.a041827

Statistics South Africa (2012). South African Standard Classification of Occupations (SASCO) 2012. Pretoria: Statistics South Africa. 
Statistics South Africa (2018). 'Labour market dynamics in South Africa 2016'. Dataset. Version 1. Pretoria: Statistics South Africa [producer]. Cape Town: DataFirst [distributor]. https://doi.org/10.25828/kkzz-mr59

van der Linde, M. (2015). 'An Analysis of the Polarisation of the South African Labour Market'. MCom Dissertation. Potchefstroom: North West University.

van Seventer, D., and R. Davies (2019). 'A 2016 Social Accounting Matrix for South Africa with an Occupationally Disaggregated Labour Market Representation'. WIDER Working Paper 56/2019. Helsinki: UNU-WIDER. https:// doi.org/10.35188/UNU-WIDER/2019/690-6 


\section{Appendix A: Occupational classifications and tasks}

Following Autor et al. (2003), it has become standard to use the task-based approach to production to investigate the impact of automation. As will be seen later, we use a crude and rather outdated version of this approach, so it may seem out of place to have an extensive discussion of it here. However, we think it is important that the approach, and the data necessary to apply it, are taken further in South Africa. We therefore describe it in some detail. The approach is still evolving, both theoretically and empirically.

Standard production functions typically show how services flowing from factors of production ('capital' and 'labour') combine to produce an output flow. Improvements in factor productivity can be incorporated by measuring the service flows in efficiency units. Different labour skills and types of capital can be incorporated by disaggregation. These production functions embody, explicitly or implicitly, an EOS, representing how capital and labour interact as their relative prices change. When there are only two factor inputs, they are typically modelled as gross substitutes: when the price of one rises, producers use the other more intensively. If wages rise relative to the cost of capital services, so production is expected to become more capital-intensive, then capital substitutes for labour. When there are more than two inputs it becomes more complicated.

The task-based approach conceptualizes production as a process of completing tasks. Some of these tasks can be undertaken either by workers or by machines. This means that the providers of these tasks can be substituted for each other. Automation is expanding the range of human tasks that machines can undertake. Thus, machines ('capital') do not replace humans ('labour') entirely in production, as the canonical model seems to imply, but rather are assigned some tasks previously carried out by humans. This may show up as production becoming more capital-intensive, but that masks the fact that substitution is at the level of tasks.

Technological change does not simply change the providers of tasks. The tasks themselves also change. The 18 tasks in pin-making described by Adam Smith were all carried out by workers using tools; since then they have been replaced by machines, which do things differently. But the machines themselves require different human-delivered tasks, related not only to operating and maintaining machines, but also to designing and building the machines. Thus, although technological change displaced humans from certain tasks, it simultaneously created opportunities for them to engage in others. We will return to this later.

The task-based approach provides a more nuanced basis for representing production than the canonical approach, not only with regard to automation. As Autor says, the canonical production function implicitly conflates which factors are used with the services those factors provide (Autor 2013: 2). We agree with Acemoglu and Restrepo (2019: 7) that the task-based approach has more descriptive realism than the canonical model. However, there are still practical problems implementing the task-based approach empirically.

Economists have always recognized that production is a process of carrying out tasks. Adam Smith's iconic description of the division of labour in a pin factory mentioned above is essentially a description of the tasks that, at that time, had to be carried out to produce pins. However, the data required to describe tasks, and the analytical techniques to analyse them, precluded economists from a task-based approach to production until recently. Rather, economists often treated 'occupations', 'skills', and 'tasks' as coterminous. The occupation 'typist' required 'typing skills' and carried out 'typing tasks': a typist is a typist is a typist. Where the skills of two apparently 
similar occupations diverged sufficiently, they were defined as two different occupations and split. More nuanced data and better techniques have allowed the task-based approach to develop.

Although skills have traditionally been related to occupations, the task content of occupations themselves is not fixed over time. The skills needed to be a bank teller in 2019 are different from those needed decades ago, because the tasks involved are different. This is true for many occupations, even those typically regarded as less skilled, such as agricultural workers. The changing skills content of occupations makes labour market analysis based on occupational classifications problematic, especially when covering a long period. These problems are compounded by the current rapid pace of technological change.

The canonical production model recognized the substitutability of capital for labour. However, if labour is heterogeneous, then capital does not substitute for labour in general but for certain types of labour, depending on the tasks it undertakes.

The evolution of technology was not, however, simply one of tasks being provided by different deliverers. Some tasks disappeared in the process, and new ones emerged. The evolution of occupations referred to above was because some tasks were hived off-to other occupations or to machines-while others were taken on. As the ox replaced human power in the task of grinding, so new tasks related to managing oxen emerged in milling.

'Occupations' are conventional. ${ }^{17}$ They are part of our everyday language, so we take their meaning for granted. 'My father is an accountant' is intended to convey something about what the father does, although the interlocutors might be unaware of exactly what. We have some notion of what work is entailed in being an accountant, or a nurse, or a truck driver. But, given that the work done in an occupation not only changes over time but also can vary depending on where the person works, 'occupation' may not be the best unit to use as an analytical category or in empirical work, especially when distinguishing different types of labour inputs into production.

The task-based approach therefore takes the task as the unit of analysis in production. An occupation at a given point in time is associated with skills needed to undertake tasks.

However, there are several problems associated with using tasks as the unit of analysis. First, while we might have a precise idea of what a task entails, it is not clear what unit of measurement should be used to quantify a task. A problem with the task-based approach is the difficulty at present of identifying and measuring tasks. Occupational classifiers are increasingly gathering information on tasks associated with occupations. However, there are few agreed task classifications, especially that are useful outside the OECD. One would like to have a classification system that follows the same pattern as other systems: one digit representing high-level grouping, a second digit representing lower groupings, and so on. To the best of our knowledge this does not exist.

Second, the literature often follows optimizing methods and refers to the marginal contribution of a task (e.g. Acemoglu and Autor 2011). But production processes as assemblies of tasks are

\footnotetext{
${ }^{17}$ An indication of the conventionality of occupations is the problem of how classifiers have been dealing with occupational names across different languages. The names applied reflect the norms of the societies, so English names embody historical class distinctions in a way that French ones do not (Elias 1997: 5).
} 
probably like a Leontief production function: all tasks are necessary to complete output. The marginal product of any task would then be zero. ${ }^{18}$

As discussed by Davies and van Seventer (2020), 'substitution' can effectively be at the level of a single plant as the technology shifts from one factor combination to another. This is what microeconomic production functions attempt to capture. But even when there are no possibilities of substitution at this level — the plant is locked into a technology because of investment choices in the past - there can be substitution at more aggregated levels, essentially through compositional changes. A firm operating two plants, each with fixed skills compositions, can appear to substitute as it shifts production from one to the other. Similar effects operate at the level of an industry or sector and for the whole economy. Changes in output composition can show up as 'substitution'. So South Africa can appear to overcome its skills constraint by shifting to less skill-intensive production. In Davies and van Seventer (2020) an accounting decomposition of labour market changes between 1993 and 2017 was undertaken. It was emphasized there that such decompositions do not show causality. It was also found that while there has been some polarization, it is rather mild. It was suggested that this is because technology in South Africa lags trends elsewhere. In this paper we examine the implications of South Africa catching up with the global trends.

Many of the papers incorporate a strong subjective supply side, assuming that the task provider makes an important input into deciding whether to undertake a task or not. The Roy model of self-selection into tasks or occupations is widely used (Roy 1951). Our concern is much more with the demand side. Although labour supply considerations are important in South Africa, especially regarding supplies of skills, the high unemployment rate suggests that it is a lack of demand that is the dominant problem.

The standard literature gets around the commodity composition effect by assuming a single good is produced. If automation changes income distribution and there are significant differences in patterns of consumption between the classes, there may be an induced compositional effect. In an open economy this could also arise if automation affects import and export patterns. However, it is likely that these effects will be small.

Following Acemoglu and Restrepo, we can envisage tasks at any point in time as being ranked from most automated to least, with a boundary dividing automated from non-automated. Automation can then be represented by a shift in this boundary which displaces labour. However, since automation also creates new labour tasks-basically machine minding-tasks can also expand.

18 Kalle Moene has pointed out that this has similarities with the O-ring theory of development (personal communication). 


\section{Appendix B: CES production function}

We have

$$
Y=F\left(Q_{A}, Q_{R}, Q_{M}, Q_{K}, Q_{E}\right)
$$

where $Y$ is value added in the sector, $A$ is abstract labour, $R$ is routine labour, $M$ is manual labour, $K$ is other capital, and $M$ is equipment. $Q$ is the flow of services from the subscripted factor input.

If we put these into a standard CES, the EOS between any pair is the same as for any other pair. We there create a composite routine factor, $F$ :

$$
Q_{F}=\alpha_{F} \cdot\left[\delta_{R} \cdot\left(A_{R} \cdot Q_{R}\right)^{-\rho_{F}}+\delta_{E} \cdot\left(A_{E} \cdot Q_{E}\right)^{-\rho_{F}}\right]^{-\frac{1}{\rho_{F}}}
$$

or alternatively:

$$
Q_{F}=\alpha_{F} \cdot\left[\sum_{n} \delta_{n} \cdot\left(A_{n} \cdot Q_{n}\right)^{-\rho_{F}}\right]^{-\frac{1}{\rho_{F}}} \quad n=R, E
$$

where

$Q_{F}$ is the quantity of the composite routine factor;

$Q_{n}$ is the quantity of input $n=R, E$;

$\alpha_{F}$ is a shift parameter;

$\delta_{F}\left[0 \leq \delta_{n} \leq 1\right.$ and $\left.\sum_{n} \delta_{n}=1\right]$ is a distributional parameter;

$A_{n}\left[0<A_{n}\right]$ is a factor-specific productivity parameter; and

$\rho_{F}\left[-1<\rho_{F} \leq \infty \quad \rho_{F} \neq 0\right]$ is a substitution parameter whose value is given by $\rho_{F}=\frac{1}{\sigma_{F}}-1$ , where $\sigma_{F}$ is the EOS. We can call it the intra-routine EOS.

This feeds into a higher level:

$$
Y=\alpha \cdot\left[\delta_{F} \cdot\left(A_{F} \cdot Q_{F}\right)^{-\rho}+\delta_{A} \cdot\left(A_{A} \cdot Q_{A}\right)^{-\rho}+\delta_{M} \cdot\left(A_{M} \cdot Q_{M}\right)^{-\rho}+\delta_{K} \cdot\left(A_{K} \cdot Q_{K}\right)^{-\rho}\right]^{-\frac{1}{\rho}}
$$

or, alternatively:

$$
Y=\alpha \cdot\left[\sum_{i} \delta_{i} \cdot\left(A_{i} \cdot Q_{i}\right)^{-\rho}\right]^{-\frac{1}{\rho}} \quad i=A, M, K, F
$$

Deriving the optimality conditions in the standard way, we get the demand for factors: 


$$
\begin{aligned}
& w_{L}=w_{F} \cdot F \cdot \frac{\delta \cdot\left(A^{L}\right)^{-\rho} \cdot L^{-\rho-1}}{\left[\delta \cdot\left(A^{L} \cdot L\right)^{-\rho}+(1-\delta) \cdot\left(A^{M} \cdot M\right)^{-\rho}\right]} \\
& w_{L}=w_{F} \cdot F \cdot \frac{\delta \cdot\left(A^{L}\right)^{-\rho} \cdot L^{-\rho-1}}{\left(\frac{F}{\alpha}\right)^{-\rho}} \\
& L=\left[\frac{w_{F}}{w_{L}} \cdot \alpha^{-\rho} \cdot \delta \cdot\left(A^{L}\right)^{-\rho}\right]^{-1-\rho} \cdot F \\
& M=\left[\frac{w_{F}}{w_{M}} \cdot \alpha^{-\rho} \cdot \delta \cdot\left(A^{M}\right)^{-\rho}\right]^{-1-\rho} \cdot F \\
& \delta_{i}=\frac{w_{i} Q_{i}^{1+\rho}}{\sum_{f} w_{f} Q_{f}^{1+\rho}} \\
& \delta_{R}=\frac{w_{R}^{1+\rho} L_{R}^{1+\rho}}{w_{R} L_{R}^{1+\rho}+w_{M} M^{1+\rho}}
\end{aligned}
$$

Table B1: Numbers of employees in each class, 2016

\begin{tabular}{lcccc}
\hline Susceptibility & \multicolumn{3}{c}{ Scope } & \multirow{2}{*}{ Total } \\
\cline { 2 - 4 } & Low & Medium & High & (227,123 \\
Low & 337,574 & 48,919 & $\mathbf{6 1 3 , 6 1 5}$ \\
Medium & 503,690 & 164,644 & 350,611 & $\mathbf{1 , 0 1 8 , 9 4 5}$ \\
High & 667,908 & 812,530 & 159,725 & $\mathbf{1 , 6 4 0 , 1 6 3}$ \\
Total & $\mathbf{1 , 5 0 9 , 1 7 2}$ & $\mathbf{1 , 2 0 4 , 2 9 6}$ & $\mathbf{5 5 9 , 2 5 4}$ & $\mathbf{3 , 2 7 2 , 7 2 3}$ \\
\hline
\end{tabular}

Source: authors' construction. 


\section{Appendix C: Measuring susceptibility}

Several studies have assessed the size of the potential impact of automation (Arntz et al. 2016, 2017; Autor and Salomons 2018; Frey and Osborne 2013). The OECD has published a series of working papers (see, inter alia, Breemersch et al. 2017; Nedelkoska and Quintini 2018; Parolin 2019). In their highly cited and influential paper, ${ }^{19}$ Frey and Osborne surveyed engineering experts' assessments of the potential automatability of tasks. They then ascribed these to occupations in the USA and, using employment numbers, assessed the risk to jobs. They concluded that as many as 47 per cent of employees in the USA are in jobs that could be automated in the next two decades. Studies of other countries using the same methodology find similarly high figures.

However, Arntz et al. (2016) argue that the 'occupational approach' used by Frey and Osborne assumes that the automation risk applies across the board to an occupation, whereas only certain tasks within the occupations are automatable. Using this more nuanced 'task approach', they find that only 9 per cent of jobs in the USA are at risk. When they apply it to other OECD countries they find similarly low levels (from 6 per cent of jobs in Korea to 12 per cent in Austria (Arntz et al. 2016: 25)). This highlights the importance of the task-based approach.

Arntz et al. do, however, find that risk of automation is significantly higher in jobs requiring lower levels of education than higher. They conclude:

This suggests that low educated workers likely will bear the brunt of adjustment costs to technological change in terms of requirements for further training and occupational retraining. Moreover, for this group of workers, regaining the competitive advantage over machines by means of upskilling and training may be difficult to achieve, especially since the speed of the current technological revolution appears to exceed the pace of its predecessors. (Arntz et al. 2016: 25)

This is a common finding. Frey and Osborne conclude their paper:

Our model predicts a truncation in the current trend towards labour market polarisation, with computerisation being principally confined to low-skill and lowwage occupations. Our findings thus imply that as technology races ahead, lowskill workers will reallocate to tasks that are non-susceptible to computerisation i.e., tasks requiring creative and social intelligence. For workers to win the race, however, they will have to acquire creative and social skills. (Frey and Osborne 2013: 48)

This has particular relevance for South Africa. It suggests that not only are jobs of the less well educated most at risk, but the people currently in those jobs are likely also to be less well prepared for reskilling as a way of mitigating the impact.

Frey and Osborne estimate probabilities that occupations are at risk from computerization (Frey and Osborne 2013). Our analysis is in terms of sectors rather than occupations. We therefore mapped their occupations to those in SASCO and used the 2016 LMD data (Statistics South Africa

\footnotetext{
${ }^{19}$ As of 18 August 2020 it had 6,355 citations in Google Scholar.
} 
2018) to construct probabilities of sectors facing automation, based on their occupational structure. Figure $\mathrm{C} 1$ provides the results, ranking sectors from highest to lowest probability.

This susceptibility is based on assessments of the likely future trajectory of automation. It shows the expert view on which tasks (occupations) are likely to be automatable in the future. It does not show the likely uptake of these technologies. Given the availability of the technology, we need a different measure of the potential for uptake. This is more difficult to predict, since it depends not only on movements in relative costs, but also investment trends and other factors. We therefore use a crude measure: the uptake will be most likely in sectors that currently have high levels of routine occupations relative to machines. We use this measure in the modelling to determine where automation might happen.

This susceptibility is based on their probabilities to classify occupations into routine and nonroutine labour (strictly 'routinizable' and 'non-routinizable'). To do this we have to map their probabilities to the occupations in the South African data.

They use O*NET mapped to SOC-10. The LMD data we use for South Africa is based on SASCO-12. We therefore use a series of crosswalks to map from one to the other. More specifically, since SASCO-12 is based primarily on ISCO-08, we map from SOC-10 to ISCO08(COM) to ISCO-88 to SASCO-12.

This process allows us to assign Frey and Osborne's probabilities to each four-digit occupational class in SASCO-12. Frey and Osborne divide their probabilities into thirds, so that a probability below 0.33 is taken as at no risk, 0.33 to 0.67 medium risk, and 0.67 and above high risk. We use these to identify first those occupations that are not and those that are routinizable, taking the 0.33 probability as the cut-off. We then take within the routinizable group 0.67 as the cut-off between those that have high and low elasticities.

Most of these mappings entail a 'many to many' mapping-SOC-10 contains 878 four-digit codes. Because the mappings are not perfect for some South African codes, some averaging is required. 
Figure C1: Susceptibility of sectors to automation, South Africa 2016

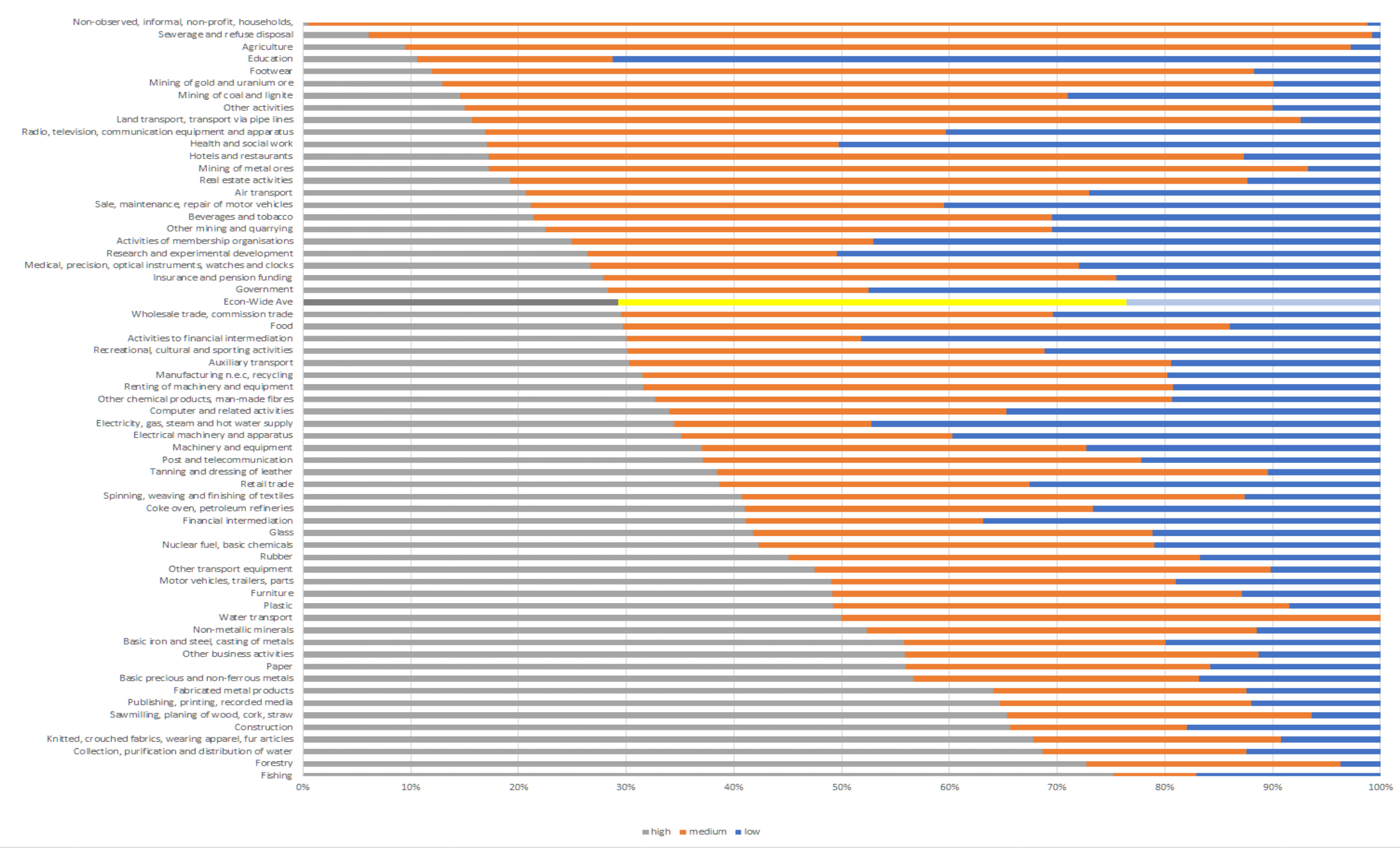

Source: authors' construction. 